\title{
Recent advances in therapy for sexual offenders
}

\section{Mairead Dolan}

Address: Centre for Forensic Behavioural Science, Victorian Institute of Forensic Mental Health, Locked Bag 10, Fairfield, Victoria, 3078, Australia Email: mairead.dolan@forensicare.vic.gov.au

FI000 Medicine Reports 2009, I:45 (doi:10.3410/MI-45)

The electronic version of this article is the complete one and can be found at: http://FI000.com/Reports/Medicine/content/I/45

\begin{abstract}
This report focuses on recent policy, and academic and clinical developments in the therapeutic management of sex offenders, including the need for more robust assessment and risk management protocols. Information is provided on current thinking about psychological and pharmacological interventions. Meta-analytic studies clearly indicate that cognitive behavioural and relapse prevention programmes are the most effective intervention, but there is a small amount of literature suggesting that pharmacological treatments may have some utility. With advances in our understanding of the neural substrates of deviant sexual arousal we may be able to develop and trial novel neuropharmacological agents that target dysfunctional neurochemical circuits in this field.
\end{abstract}

\section{Introduction and context}

Increasing public concern about sexual offending and the risks these offenders pose in the community has led to a wave of new legislative measures to monitor and manage this group in the UK and elsewhere. For example, the Violent and Sex Offenders Register (ViSOR) 2003 and the Sexual Offence Prevention Orders (SOPO) allow UK police and probation services to track and locate high-risk offenders in the UK. In recent years governments have also significantly increased resources for probation services to run structured group-based intervention programmes for sex offenders.

Sex offences account for approximately $1 \%$ of all recorded crime in the UK (Home Office Statistics, 2006). Internationally, crime surveys suggest that sexual assaults are more common than official reports suggest, with under-reporting influencing the accuracy of statistical recording. Sex offenders are a heterogeneous group and a number of attempts have been made to categorise them based on offence type, victim type, and motivation [1]. Victim-based typologies have proved particularly difficult in light of evidence that some offend against a range of male and female victims, child and adult victims, and related and unrelated victims [2].
A comprehensive clinical assessment is essential in understanding the nature and motivation for the perpetrator's behaviour, their likely treatment needs, and their future risk to society. Multiple sources of information are required given the high levels of denial and minimisation of the seriousness and impact of their offences noted among sex offender cohorts [3]. Standard assessments should cover developmental history, family history, psychosexual history, relationships, education/ employment, substance misuse, psychiatric/medical history, forensic history, and attitude to offending behaviour.

Over the last two decades there has been a growth in interest in the development of specific sex offender risk assessment tools. Large-scale meta-analytic reviews [4,5] have identified static risk predictors that have been combined to develop sex offender risk prediction tools such as the STATIC-99 [6] and the Sex Offender Risk Appraisal Guide [7]. Although the latter measures can predict sexual recidivism quite well, more recent work has focused on identifying more dynamic risk factors that inform sex offender treatment planning and management, such as deviant sexual interests and antisocial orientation [5]. This has resulted in the development of assessment tools that combine static 
and dynamic risk factors into measures, such as the Sex Offender Need Assessment Rating (SONAR) [8], Sexual Violence Risk-20 (SVR-20) [9], Risk for Sexual Violence Protocol (RSVP) [10], and Violence Risk Scale - Sexual Offender Version (VRS-SO) [11].

Cognitive behavioural therapy (CBT) is the preferred mode of treatment for sex offenders according to the Association for the Treatment of Sexual Abusers (ATSA), 2001. In the UK the prison-based group Sex Offender Treatment Programme (STOP) and its evaluation project (STEP) have provided a robust evidence base to suggest the value of long-term CBT-based interventions for sex offenders $[12,13]$. The primary goals of these interventions are to reduce the risk of reoffending by cognitive restructuring. This includes challenging cognitive distortions and attempts at justification and minimisation of offending behaviour. It also looks at improving victim empathy and enabling the perpetrator to develop relapse prevention skills. Other key goals are to improve social competence, for example, by improving self esteem, managing negative emotional states, and problem solving $[1,14]$.

Relapse prevention is another key area of work that can help sex offenders, released into the community after intensive CBT interventions, to identify person-specific sequences of events/behaviours (such as cognitive distortions, deviant sexual arousal, poor social skills, and intimacy difficulties) that have previously lead them to offend. As there are multiple pathways leading to relapse and an increased risk of reoffending, it has been suggested that clinicians should encourage a self-regulation model and attempt to understand the perpetrator's deviant sexual offending behaviour in terms of their victim approach strategy (for example, grooming, coercing or threatening victims).

Previous meta-analyses on the efficacy of sex offender treatment programmes have shown that CBT-based interventions can decrease recidivism, but that this decrease is modest $[4,12,15]$.

\section{Recent advances}

Recently, a 'pathways' model of child sexual abuse has been developed which can also be applied to adult sexual assault [16]. The latter model suggests there are four psychological mechanisms that operate distinctly or interactively to lead to sex offending behaviour. These include intimacy deficits, deviant sexual scripts (that is, an internal representation of sexual behaviour that deviates from the societal norm), emotional dysregulation, and distorted cognitions. Each of these mechanisms can form the basis of cognitive-behavioural intervention programmes.

A number of studies looking into the clinical assessment of sex offenders suggest that there are a range of psychometric measures that have utility in assessing distorted cognitions, personality factors, denial and minimisation, and motivation to engage in treatment [17]. Contradictory research findings have lead to questions about the utility of penile plethysmography in the assessment of sexual preferences and risk, although there seems to be some evidence to support its use in sub-typing rapists $[18,19]$. The use of postconviction polygraphy in disclosure of offending behaviour is currently the subject of much debate given the generic problems that have been recorded about strategies that can be used to deceive using this measure [20].

Pharmacological treatments for reducing sexual drive, and therefore sexual behaviour, include anti-androgens and hormonal agents such as medroxyprogesterone acetate (MPA), cyproterone acetate (CPA), luteinising hormone-releasing hormone (LHRH) agonists and selective serotonin re-uptake inhibitors (SSRIs). CPA rather than MPA has been used more extensively across continents, but both drugs have been shown to be effective in reducing testosterone levels [19]. More recent work has focused on LHRH, which is a hypothalamic decapeptide that decreases testosterone and dihydrotestersterone release through its inhibitory effects on gonadotrophin secretion. Although most studies are open-label and of small sample size, the findings suggest that this agent has promise given its prolonged action and the fact it can be administered intramuscularly or subcutaneously, with fewer side effects than CPA and MPA. Although there is little literature looking at the effects of combining CBT with pharmacological treatments, one small-scale study of five subjects suggested that CBT combined with the LHRH agonist leuprolide reduced paedophilic fantasies and masturbation (supported by objective measures of arousal), and none of the cohort reoffended within the 2 years of the study [21].

The use of SSRIs in sex offenders has been reported in the literature for over 15 years but there have been no published randomised control treatment trials using these agents. There are a number of small-scale openlabel studies suggesting evidence of a reduction in sexual obsessions over a short-term period $[19,22]$. The use of SSRIs needs further scrutiny in terms of offender pathology, study design, and outcome measurement. 
Some recent carefully designed studies looking into the effects of relapse prevention programmes on recidivism have failed to find significant treatment effects [23]. However, a very recent well-designed study from Canada [11] suggests that long-term (over 20 years) recidivism rates can be reduced in moderate- to high-risk offenders. The latter study was based on a high-intensity CBTorientated inpatient sex offender programme that focused on the 'What Works' principles of effective correctional treatment [24-26]. Most reviews highlight the need for high quality methodologically rigorous studies that can be used in future meta-analytic studies on sex offender treatment programmes.

As yet, there are only a limited number of studies demonstrating the incremental value of adding dynamic variables (such as deviant sexual interests and antisocial orientation) to standardised, fairly static, risk assessment tools [27-29]. The development and validation of combined static and dynamic risk assessment tools with a focus on risk management, such as the VRS-SO scale, will be invaluable in driving evaluations on the sex offender treatment programme. There has been a limited, but nonetheless potentially significant, advance in our understanding of the neural basis of deviant sexual arousal, particularly in paedophilia. For example, brain regions associated with the control of behaviour that are involved in processing erotic stimuli in healthy individuals have very recently been shown to have a reduced level of activation in paedophilic patients during paedophilic visual erotic stimulation [30]. This suggests an impaired recruitment of key structures that might contribute to an altered sexual interest of these patients toward adults. Findings like these need to be replicated as they will enhance our understanding of the nature of dysfunction in the neural networks involved in deviant sexual behaviour and may lead to more targeted neurocognitive and neuropharmacological treatment interventions.

\section{Implications for clinical practice}

There is now reasonable evidence to suggest CBT combined with relapse prevention, intensive residential, and community-based sex offender treatment programmes reduces the risk of recidivism. Further work is needed to explore the effects of combined CBT and pharmacological treatments. More work is also needed on the development of manualised treatment protocols, which are process oriented so that clinicians can assess which aspects of the core programme result in a good outcome in relation to offender profile, need, and risk. The development and validation of a number of specific risk assessment/management tools should help clinicians identify key treatment targets for offenders and assist in the process of identifying those who will need more intensive residential CBT and relapse prevention programmes. Denial and minimization of offending behaviour is a key challenge for clinicians working in this field. Some work is being done on the use of postconviction polygraphy to detect non-disclosure, but it is too early to advocate its use in routine clinical practice. Much more rigorous pharmacological treatment trials are required in the sex offender treatment field before these agents can be seen as primary, or indeed routine, adjunctive components of treatment planning.

\section{Abbreviations}

ATSA, Association for the Treatment of Sexual Abusers; $\mathrm{CBT}$, cognitive behavioural therapy; $\mathrm{CPA}$, cyproterone acetate; LHRH, luteinising hormone-releasing hormone; MPA, medroxyprogesterone acetate; RSVP, Risk for Sexual Violence Protocol; SONAR, Sex Offender Need Assessment Rating; SOPO, Sexual Offence Prevention Orders; SSRI, selective serotonin re-uptake inhibitor; STEP, Sex Offender Treatment Evaluation Programme; STOP, Sex Offender Treatment Programme; SVR-20, Sexual Violence Risk-20; ViSOR, Violent and Sex Offenders Register; VRS-SO, Violence Risk Scale - Sexual Offender Version.

\section{Competing interests}

The author declares that she has no competing interests.

\section{References}

I. Ward T, Hudson SM: A Self-Regulation Model of Relapse Prevention. In Remaking Relapse Prevention with Sex Offenders: A Sourcebook. Edited by Laws DR, Hudson SM, Ward T. Thousand Oaks, CA: Sage; 2000:79-10I.

2. Abel GG, Becker JV, Cunningham-Rathner J: Complications, consent, and cognition in sex between children and adults. Int J Law Psychiatry 1984, 7:89-103.

3. Marshall WL: Treatment effects on denial and minimisation in incarcerated sex offenders. Behav Res Ther 1994, 32:559-64.

4. Hanson RK, Bussière MT: Predicting relapse: a meta-analysis of sexual offender recidivism studies. J Consult Clin Psychol 1998, 66:348-62.

5. Hanson RK, Morton-Bourgon K: Predictors of sexual recidivism: An updated meta-analysis. Corrections User Report 2004-02: Public Safety and Emergency Preparedness Canada (Ottowa, Ontario). [http:// www.publicsafety.gc.ca/res/cor/rep/_fl/2004-02-pred-se-eng.pdf].

6. Hanson RK, Thornton D: Improving risk assessments for sex offenders: a comparison of the three actuarial scales. Law Hum Behav 2000, 24: I19-36.

7. Quinsey VL, Harris GT, Rice ME, Cormier CA: Violent Offenders: Appraising and Managing Risk. Washington, DC: American Psychological Association; 1998.

8. Hanson RK, Harris AJ: A structured approach to evaluating change among sexual offenders. Sex Abuse 2001, I3:105-22.

9. Boer DP, Hart SD, Kropp PR, Webster CD: Manual for the Sexual Violence Risk - 20: Professional guidelines for assessing risk of sexual violence. Vancouver, British Columbia: Simon Fraser University, Mental Health, Law and Policy Institute; 1997.

10. Hart SD, Laws DR, Kropp PR: The risk-need model of offender rehabilitation. In Theoretical Issues and Controversies In Sexual 
Deviance. Edited by Ward T, Laws DR, Hudson SM. London: Sage; 2003:338-54.

II. Wong S, Olver ME, Nicholaichuk TP, Gordon A: The Violence Risk Scale - Sexual Offender version (VRS-SO). Saskatoon, Canada: Regional Psychiatric Centre and University of Saskatchewan; 2004.

12. Hanson RK, Gordon A, Harris A], Marques JK, Murphy W, Quinsey VL, Seto MC: First report of the collaborative outcome data project on the effectiveness of psychological treatment for sex offenders. Sex Abuse 2002, 14:169-94; discussion 195-7.

13. Friendship C, Mann R, Beech A: The prison-based Sex Offender Treatment Programme - an evaluation. London Home Office Development and Statistics Directorate Research Findings No. 205; 2003, [http://www.homeoffice.gov.uk/rds/pdfs2/r205.pdf].

14. Lockmuller M, Beech A, Fischer D: Sexual offenders with mental health problems: epidemiology, assessment and treatment. In Handbook of Forensic Mental Health. Edited by Soothill K, Rogers P, Dolan M. Cullompton, Devon: Willan Publishing; 2008:446-479.

15. Hanson RK, Broom I, Stephenson M: Evaluating community sex offender treatment programs: A 12 year follow up of 724 offenders. Can J Behav Sci 2004, 36:87-96.

16. Ward T, Beech AR: An integrated theory of sexual offending. Aggress Violent Beh 2006, II:44-63.

17. Serin RC, Mailloux DL: Assessment of sex offenders: lessons learned from the assessment of non-sex offenders. Ann $N Y$ Acad Sci 2003, 989: 185-97.

18. Lalumière ML, Quinsey VL, Harris GT, Rice ME, Trautrimas C: Are rapists differentially aroused by coercive sex in phallometric assessments? Ann N Y Acad Sci 2003, 989:2I I-24.

19. Bourget D, Bradford JM: Evidential Basis for the Assessment and Treatment of Sex Offenders. Brief Treat Crisis Interv 2008, 8: I30146.

20. Meijer EH, Verschuere B, Merckelbach HL, Crombez G: Sex offender management using the polygraph: a critical review. Int J Law Psychiatry 2008, 31 :423-9.
21. Schober JM, Kuhn PJ, Kovacs PG, Earle JH, Byrne PM, Fries RA: Leuprolide acetate suppresses pedophilic urges and arousability. Arch Sex Behav 2005, 34:691-705.

22. Codispoti VL: Pharmacology of sexually compulsive behavior. Psychiatr Clin North Am 2008, 3 I:67I-9.

23. Marques JK, Wiederanders M, Day DM, Nelson C, van Ommeren A: Effects of a relapse prevention program on sexual recidivism: final results from California's sex offender treatment and evaluation project (SOTEP). Sex Abuse 2005, 17:79-107.

24. McGuire J: What Works: reducing re-offending - guidelines from research and practice. Chichester, UK: Wiley; 1995.

25. Olver ME, Wong SCP, Nicholaichuk TP: Outcome evaluation of a high-intensity inpatient sex offender treatment program. J Interpers Violence 2009, 24:522-36.

26. Seto $M C$, Marques JK, Harris GT, Chaffin M, Lalumière ML, Miner MH, Berliner L, Rice ME, Lieb R, Quinsey VL: Good science and progress in sex offender treatment are intertwined: a response to Marshall and Marshall (2007). Sex Abuse 2008, 20:247-55

27. Olver ME, Wong SC, Nicholaichuk TP, Gordon A: The validity and reliability of the Violence Risk Scale-Sexual Offender version: assessing sex offender risk and evaluating therapeutic change. Psychol Assess 2007, 19:318-29.

28. Hudson SM, Wales DS, Bakker L, Ward T: Dynamic risk factors: the Kia Marama evaluation. Sex Abuse 2002, 14:103-19; discussion 195-7.

29. Hanson RK: The assessment of criminogenic needs of sexual offenders by community supervision officers: Reliability and validity. Symposium presented at the $66^{\text {th }}$ Annual Meeting of the Canadian Psychological Association, Montreal, Quebec, Canada; 2005.

30. Schiffer B, Paul T, Gizewski E, Forsting M, Leygraf N, Schedlowski M, Kruger TH: Functional brain correlates of heterosexual paedophilia. Neuroimage 2008, 41:80-91. 